\title{
THE ART OF PSYCHOTICS*
}

\author{
RUDOLF ARNHEIM
}

\author{
Visiting Professor, University of Michigan
}

l.

Incomprehensible art is a modern phenomenon of our civilization. We attribute it to the rather unique combination of two factors. There has been a splitting-up of our cultural heritage, by which commonly shared ideas have given way to private conceptions nurtured by special groups or individuals. Correspondingly the symbolic images representing these ideas have come to reveal their meaning only to the happy few. At the same time, however, our century has generated the democratic expectation that works of art be understandable to everybody, so that the kind of esoteric message that was confined in earlier periods to those able to receive it now faces the population as a whole, an audience unprepared for it.

This gulf between art and its public became particularly apparent when the artist in his presentations estranged himself by an unfamiliar style of visual form, that is, when he deviated from the lifelikeness that citizens had come to expect from paintings or sculpture. In the past, a viewer of Botticelli's Birth of Venus might have been unaware of the picture's mythological and humanistic connotations, but he had little trouble deciphering and being moved by the airy figures his eyes saw; whereas the visual idioms of the modern artist stop the unprepared visitor at the very first step of his approach.

Add to this the protective unwillingness of people at most other times and places to pay attention to any form of art not in conformity with their own. Incomprehensibility was no issue as long as one felt no urge to understand. In our own setting until a century ago it was possible to dismiss as barbarian not only the art of "primitive" tribesmen but also much of what came over from Asia. Similarly, as the art historian Georg Schmidt has pointed out, three "outsider" varieties of art were excluded from recognition: the folk art of the peintres naifs and the art work of children and mental patients $(3$, p. 28$)$. It was taken for granted that inability and derangement made such products unfit for aesthetic consideration.

The first attempts to understand and appreciate the art of the insane coincide with the first impact of modern art upon Western Europe. In 1872, Auguste Ambroise Tardieu, a Paris physician published a "medical-legal study of insanity," in which he reproduced a drawing by a schizophrenic and pointed to the psychiatric and artistic interest of such work [15]. By that time, Impressionist painting was in full swing. A few years later, the Italian art historian Corrado Ricci published the first book on the art of children [14]. The profound impression exerted by Japanese woodcuts and African sculpture around the turn of the century is well known.

The art of Asia and Africa, although strange to Western eyes, derived of course from clearly established traditions of its own. A curious, very dif. ferent problem was posed by the art work of psychotics and children and, to some extent, by folk artists. These products were all but untouched by the artistic climate of their setting. They seemed to burst into bloom from nowhere, created by untrained and uninfluenced laymen. Also professional artists, struck by mental illness, suddenly produced

*Requests for reprints should be sent to Dr. Rudolf Arnheim, 1133 South Seventh St., Ann Arbor, Mich. 48103. 
images unrelated to the style of art they had practiced and often much superior to anything they had done before. We have reasons to suspect that if we knew more such work of the "outsiders" done in different periods and places, we would find the similarities outweighing the differences. The drawings of young children look much the same all over the world. There is a kinship of folk art, whatever its origin. And the same might well be true for the art work of psychotics.

We are beginning to realize that this family resemblance is not simply due to deficiencies. Children's drawings share a common style not just because they all are done by persons of limited skill. The art work of psychotics is not principally characterized by the symptoms of degeneration or disorganization, present though these symptoms often are. No, what we seem to face here is the manifestations of an art that rises from the very roots of human perceiving and thinking, from the elementary core of mental functioning, not yet modified by the influences of education, training, and other cultural conventions. It looks as though we are afforded a glimpse at the human mind "as such." As W.B. Yeats puts it in one of his poems:

I'm looking for the face I had

Before the world was made (16, p. 266).

This new and perhaps disconcerting perspective on the art of the "outsiders" was suggested already in one of the pioneer studies, The Art of the Insane, published in 1907 by the French psychiatrist Marcel Réja [12]. As quoted by Alfred Bader, Réja believed that "it is the privilege of genius to reveal to us the nature and the springs of the human spirit, but only the insane can directly confront us with these same insights, clumsily but purely, in their primordial bareness. Granted that the works of the insane dazzle us less than those of the geniuses, but they give us a better chance to perceive the essentials clearly." According to Réja, the art of the insane provides us, more intensely than other art, with a "raccourci expressif de l'état actuel des affaires," that is, with an expressive condensation of the given state of affairs $(6, p .18)$.

These are strong words, but they find a sympathetic hearing in the recent inclination to revive some of the ancient respect for the mentally deranged and to consider them privy to a seer's wisdom, from which the normal undisturbed mind is barred by its practical reasonableness. It is a tempting Romantic response to a tendency to judge mental illness only negatively. One need not go so far as to shift the burden of insanity to modern society and to proclaim schizophrenia as the appropriate way of handling this mad life of ours. To deny the distortions in mental illness and its manifestations is to be blinded by a fashionable resentment of established values. But unquestionably the best specimens of the art created by mental patients cannot but open one's eyes to the extraordinary enrichment they have to offer.

The problems raised by these considerations are impressively presented in recent European publications, especially in the beautifully illustrated work Zwischen Wahn und Wirklichkeit, which has just been completed by two leading experts in the field, Alfred Bader, a psychiatrist on the medical faculty of the University of Lausanne, and Leo Navratil, who practices at the mental institution of Klosterneuburg in Austria [6]. The book contains the most thorough survey of the studies on psychotic art ever published, together with a theory of creativity, a number of case studies, and a section on diagnostic and therapeutic aspects. There are many color plates of outstanding quality and hundreds of black and white examples.

The only earlier attempt at an extensive analysis of our subject is the book by the German psychiatrist Hans Prinzhom, recently translated into English under the title Artistry of the Mentally Ill. The German original was first published in 1922 and reissued in 1968 [11]. Significantly, Prinzhorn had started as an art historian in Vienna, and his aesthetic outlook and trained eye determined his approach and the selection of his examples. Influenced by the philosopher and graphologist Ludwig Klages, he proceeded in his thinking from the fundamental urge of expression, which manifests itself in the six roots of what he called the Gestaltungsdrang, i.e., the desire to create tangible form. This desire derives from the play instinct and the instinct of decoration or ornamentation and is developed into tangible shape by two tendencies, toward order and toward pictorial representation. Finally the need to symbolize endows the created form with a meaning that, in Prinzhorn's opinion, lies outside of visual appearance. These criteria, derived from the theory of art more in general and referring to all art, were used by Prinzhorn to describe the affinity of psychotic art to the work of Expressionists and 
Surrealists in the twentieth century. He used the same categories to define the particularities of the psychotic specimens he had selected from the circa 5000 examples collected at the clinic of the University of Heidelberg from sources in Germany, Austria, Switzerland. Italy, and the Netherlands.

The works gathered by Prinzhorn were the spontaneous creations of patients, not solicited or guided by therapists. The output, therefore, was less systematic than is our present material. Much less is known about the circumstances under which much of it was produced. On the other hand, the uninfluenced spontaneity of this abundant production in institutions everywhere makes the phenomenon all the more impressive and valuable. Bader also points out that the recent introduction of drug therapy has widely reduced the symptoms of psychosis, among them the spontaneous urge to artistic activity, so that much art work today is produced in group sessions conducted by therapists $(6, p .261)$.

Prinzhorn's emphasis on the artistic quality of the works he had selected and their affinity to prominent trends to modern art did not fail to attract the attention of the art world. The book confirmed views that had begun to form in the minds of artists and critics. The art historian Franz Meyer points in this connection to an entry in Paul Klee's diary written in 1912 after a visit to the third exhibition of Kandinsky's group Der Blaue Reiter in Munich $(3$, p. 37; 9, \#905). Klee asserts that for the understanding of modern art one can draw on sources other than those of official art history: "There are also primordial beginnings of art which can be found more readily in ethnographic collections or at home in the nursery. Do not chuckle, reader! The children, too, know how to do it, and the fact that they can is enlightening. The more helpless they are, the more instructive the examples they have to offer, and they, too, have to be protected early against corruption. An analogous phenomenon is the works of the mentally ill, and disparaging references to childish behavior or insanity fail to hit the mark. All this has to be taken most seriously, more seriously than all the art museums, when we approach the task of reform."

What are the aesthetic features that give the best art of psychotic patients, and especially of schizophrenics, their striking modernity? Principally they are two, both distinguished by the abandonment of the naturalistic tradition of Renaissance art. One of these characteristics is the unrestrained use of the direct expression of color and shape to give visual appearance to passion, fright, joy, and other elementary human experiences in their strongest immediacy. This tendency overrides the concern with "correct" naturalistic portrayal. It is the earmark of the various styles grouped by art historians under the heading "expressionism," as opposed to "classicism." In describing this feature Navratil makes two unfortunate choices $(6$, p. 110). Following a proposal of the literary historian Ernst Robert Curtius, who suggested the term Mannerism for "all literary tendencies opposed to classicism," Navratil describes the expressionist quality of psychotic art as Mannerism and thereby limits its character unduly $(7 ; 8$, pp. 9, 229). Mannerism, a term applied by Vasari to Michelangelo's late works, developed as a style during the sixteenth century. Typical was a forceful distortion and elongation of figures, a brittle elegance conveying maximal visual tension, a self-conscious stress on decorative form. Mannerism was a subspecies of expressionism, in no way encompassing anticlassicist art as a whole. It is true that a good deal of psychotic art is distinctly "mannered," but to focus on this pathological trait and to make it stand for expression in its broader meaning is to draw attention away from the deeper, more universal, and entirely positive quality that Prinzhorn had discerned in his best specimens.

Navratil is equally unfortunate in using the term "expression" interchangeably with "physiognomisation" (6, p. 83). Here again a narrow, relatively unimportant trait, namely the imposition of human features - e.g., a human face applied to a drawing of the sun - is made to stand for the much broader, much more essential, and largely positive trait. It is the freedom of strong, spontaneous expression that makes psychotic art work deserve attention beyond its value for psychiatric diagnosis and therapy.

A second feature of psychotic art to be mentioned here is the conformity of drawings and paintings to the particular requirements of the twodimensional medium. Once again we are dealing with a characteristic trait of any art that is not coerced by the requirements of naturalistic representation. Psychiatrists have noted in this respect the resemblance to primitive art, especially the work of children. But they have tended to describe some of these formal characteristics as "pathognomic" signs, thereby conveying the notion that they are somehow specifically generated by pathology. Also 
by labeling them as a "regression" to an infantile level they overlook the positive aesthetic and therefore human value of these formal features. Most telling in this respect is a systematic table of traits of schizophrenic imagery drawn up by the psychiatrist Helmut Rennert in a book first published in $1962(13 ; 6$, p. 60). Among many other features he mentions the absence of perspective, and the maplike representation "from above," the lack of shading and volume, etc. These and other similar traits, certainly characteristic of some patients' art work, must be understood as fundamental, positive characteristics of much art outside the range of our own naturalistic Renaissance tradition.

More in general, the failure to recognize the raison d'être of certain formal characteristics illustrates one of the principal handicaps in our interpretations of figural art. It is a handicap by no means limited to psychiatrists. There is a widespread tendency to account for the properties of images by what the artist is assumed to have observed, or failed to observe, somewhere in the world of his visual experience. This leads to misinterpretations, which can be avoided if one realizes that the particular medium in which an image is created suggests definite procedures, obeyed under favorable historical conditions and overridden in our own naturalistic tradition [2] .

As a striking example of this influence of the medium I mention the visual "puns," frequently observed in schizophrenic art. "Extricated from their natural context, the limbs and trunks of ani$\mathrm{mal}$ and man combine without restraint on the basis of purely formal affinities: arms are fitted with birds' heads instead of hands, swans' necks lead into human buttocks" $(1$, p. 148). It would be futile to search for the models of these particular combinations of heterogeneous items in the experiences, hallucinations, or fantasies of the patients. But as soon as we remember that what is produced here are shapes and colors on paper we realize how easily one shape slips into another similar one, regardless of the disparity of the subject matter. None of the coercion it would take to fuse these items into a unified object in a world controlled by the physical reality of things is required to make shape take to shape on paper, to develop a headdress into a little creature of its own or to display a glaring eye at a place where it has no right to be.

A similar explanation holds for the horror vacui often noticed in schizophrenic pictures. Every nook is densely filled with shapes, nothing is left empty. To account for this ubiquity of shapes by reference to the observed and intended subject matter would, here again, be futile, whereas in the world of the drawing paper every empty spot is an invitation. We ourselves give in to the same temptation in our doodles on the telephone pad but fail to apply this knowledge to the art productions of patients. The same is true for the stereotypic repetition of themes and also for the reciprocity of figure-ground rela. tions, e.g., for the "birdies" with which Adolf Wölfli, the subject of a famous case study by Walter Morgenthaler, filled the "negative spaces" of his paintings $(10 ; 6$, p. 189). The result is a dense packing of the pictorial surface, in which each item is object and background at the same time. One observes the kind of ambiguity that is so well known from the clearly schizoid form play in the work of the artist M. Escher and other Surrealists.

The usual distinction between figure and ground comes to us from our dealings with the outer world, in which we have to tell circumscribed objects from the space surrounding them. It is the biological base of all sensory discrimination. Similarly any picture deriving from an interest in "things" of whatever nature requires this basic distinction. What needs an explanation in the pictures of schizophrenics is not where they got the conception of the gapless world they create but what makes them tolerate and even enjoy it on paper. Since the art medium's nonreferential characteristics invite the complete filling of space, the psychologist must speculate on the lack of the normal countertendency that controls the healthy human mind when it deals with the things of the world. The schizophrenic withdrawal from active intercourse with the environment is the key agent operative here. Not what the diseased mind invents but what it allows to happen is decisive for this particular aspect of its activity.

\section{REFERENCES}

1. ARN HEIM, RUDOLF (1974) Art and Visual Perception. Revised edition. Berkeley and Los Angeles: University of California Press.

2. ARNHEIM, RUDOLF (1972) Inverted perspective in art. Leonardo, Spring, 125-135.

3. BADER, ALFRED (ED.) (1975) Geisteskrankheit, bildnerischer Ausdruck und Kunst. Bern: Huber.

4. BADER, ALFRED (1973) Geisteskranker oder Künstler? Bern: Huber.

5. BADER, ALFRED (1972) Zugang zur Bildnerei der Schizophrenen vor und nach Prinzhorn. Confinia Psy. chiatrica, 15, 101-115. 
6. BADER, ALFRED AND LEO NAVRATIL (1976) Zwischen Wahn und Wirklichkeit, Lucerne: Bucher.

7. CURTIUS, ERNST ROBERT (1963) Europäische Liter. atur und lateinisches Mittelalter. Bern: Francke.

8. HOCKE, GUSTAV RENÉ (1957) Die Welt als Labyrinth. Reinbek: Rowohlt.

9. KLEE, FELIX (ED.) (1968) The Diaries of Paul Klee 1898-1918. Berkeley and Los Angeles: University of California Press.

10. MORGENTHALER, WALTER (1921) Ein Geisteskranker als Künstler, Bern: Bircher.

II.

It may be helpful to refer here to the cautious observations offered by Leo Navratil in a chapter on "creativity" (4, p. 131). In our own country this term has been batted around so indiscriminately that it has come to cover any behavior not derived from acquired standards. Creativity has become the darling of our daydreams. Navratil limits the term soberly to a biopsychological outflow, not neces. sarily always valuable by itself. In this sense he calls all psychotic symptoms a "creation" of the diseased mind. "Psychosis is an eruption of creativity, but creativity and banality do not exclude each other." In order to lend value to behavior, a counterdrive (Gegentrieb) must operate. This is beautifully expressed in a quotation from Morgenthaler's earlier monograph on the art work of Adolf Wölfli: "On the one hand there is the boundless drive, something titanic, trying to transcend all limits of space and time and forever in pursuit of the whole. There is a constant high pitch of emphasis, an excessive enhancement of the symbolic, a striving toward absolute freedom, violently mutilating and breaking all natural forms, and inner restlessness and passion amounting to dread, intent on stuffing everything onto a single sheet of paper, on expressing everything in a single concept. It is something mystical and demonic. But there is also the counterdrive, normative, lawful, an external calmness and objectivity that can reach a state of cool matter-offactness or even indifference, a regulating order to the point of monotony and indeed formalism and petrification" (4, p. 19). Still another author, Hermmo Müller-Suur, puts it thus: "In the artistic productions of schizophrenics two actually irreconcilable opposites coincide: the process of illness that destroys meaning and a human activity that sustains meaning" $(3$, p. 142$)$.

This most opportune reference to the sense of orderly form makes the phenomenon of psychotic art appear as an even greater miracle. It is remark-
11. PRINZHORN, HANS (1972) Artistry of the Mentally Ill. New York: Springer.

12. RÉJA, MARCEL (1907) L'art chez les fous. Paris: Mercure de France.

13. RENNERT, HELMUT (1962) Die Merkmale schizophrener Bildnerei. Jena: Fischer.

14. RICCI, CORRADO (1887) L'arte dei bambini. Bologna.

15. TARDIEU, AUGUSTE AMBROISE (1972) Etude medico-legale sur la folie. Paris: Baillière.

16. YE. TS, W. B. (1951) The Collected Poems. New York: Macmillan.

able enough that the expression of basic human experience should burst into sight with so much power and seemingly from nowhere; but it is perhaps even more astonishing that the same spontaneity should generate an often admirable sense of visual order, a quality which is frequently assumed to develop, in the artist, only through prolonged training. It looks as though the sense of form, too, is one of the basic assets of the human endowment, inherent in every mind and waiting and perhaps striving to be activated, although more often than not it is suppressed by the mores of our particular culture. This sense of form is one of the artistic qualities brought to sudden manifestation by the liberating explosion of the psychosis.

The emergence of an inherent sense of form contradicts the Romantic notion of the chaotic unconscious seething as a caldron of boiling creativity and tamed only at the level of rational consciousness. It does not sit well with Anton Ehrenzweig's much publicized notion that "in our analysis of art form we can expect that it is gestalt-bound only to the extent to which the surface mind contributed to its structure, but otherwise it is gestalt-free" $(6, p$. $33)$. On the contrary, the sense of form seems to be as deeply seated in human nature as the basic biological instincts. Does it not stand to reason that for the survival of creatures the ability to organize shape and space should be as fundamental as the desire to eat and drink and multiply?

It does seem puzzling, however, that some of the best works of schizophrenic art excel in formal composition whereas the verbal utterances of schizophrenics impress us so typically as cascades of meaningless associations. When Samuel Beckett in the sudden verbal outburst of Lucky's speech, in Waiting for Godot, imitates schizophrenia, he does so to convey something nonsensical, although per. haps mysteriously significant. It is true that schizophrenic language abounds in formal assonances and puns $(1$, p. 80$)$ but there is little resemblance be- 
tween the highly organized paintings that enchanted Prinzhorn and our modern artists and the typical "word salad" of even the more "creative" patients. They do produce raw material for poetry; but we might speculate that language depends more than visual art on an explicit coherence of subject matter.

With all our emphasis here on the aesthetic quality of some products of the disturbed mind we must not forget that we are dealing with pathology. There is plenty of psychotic art in which the onslaught of visual expression lacks formal order. The fruits of a rampant imagination fall where they may and undo one another's effect. Conversely there are many examples of an excessive dominance of form stifling the life of the artistic representation. Indeed a rigid formalism has been recognized as one of the most telling symptoms of schizophrenic art. This tendency expresses itself in a preference for symmetry in the overall composition of many of the drawings and paintings as well as in particular components. In the shaping of subject matter, for example, of human bodies neatly drawn contours define smooth curves conveying a sense of ornament but also of chilling abstractness. Simple geometrical shapes, circles, and crescents, checkerboards, triangles, stars, and stripes intermingle with elements of figural subject matter.

Where does this tendency originate? As long as interpretation relies on the misleading approach I described earlier, namely the search for external models in the perceptual experience of the image maker, no useful explanation will come forth. The world is full of geometrically simple shapes one may choose to imitate, but the preference for such shapes remains the principal fact to be understood. We come closer to an understanding when we realize that a very general tendency to attain the simplest shape available in any given situation controls the physical, physiological, and perceptual worlds. According to this fundamental rule established in the 1920 s by the gestalt theorists, simple form characterizes the basic states of physical and mental systems. Complexity is imposed upon them by modifying circumstances. This means for visual experience that the more the mind is closed off from the modulating complexity of particular experience, the more radically will the tendency toward simplest structure prevail. I have tried to deal with this phenomenon in a discussion of "levels of abstraction" in my book Art and Visual Percep- tion.

Detachment from outer and inner reality is, of course, a dominant trait of schizophrenia. Bader discusses Kontaktstörung, i.e., interference with contact, under three headings: isolation, delimitation, and enclosedness; and he quotes Prinzhorn: "Nothing out there retains a value of its own, which might impel the person to contemplate or recreate what he perceives. Everything is mere material for the self-sufficiency of an autistic, alienated psyche." This attitude leads "persons of relatively simple talent spontaneously to a form language that is more or less symbolical but in any case quite firm and consistent - a personal style" $(4$, pp. 268,22$)$.

Since the simplicity principle controls the physical as well as the mental world, it is not surprising that the basic geometrical figures and ornaments are found throughout the organic and the inorganic world, wherever configurations of forces can organize in sufficient isolation. Symmetrical and crystalline shapes abound in nature, and Bader points in this connection to the resemblance between patterns created in liquids by sound vibrations and the ornaments found in the work of the schizophrenic artist Schröder-Sonnenstern (3, p. 114). At the physiological level of visual experimentation Max Knoll and collaborators have evoked entoptic phenomena or phosphenes which display similar symmetrical ornaments when electric frequencies within the EEG range are applied to the brain [10]. In a recent systematic publication by Siegel and West on hallucinations, Mardi J. Horowitz refers to the experiments of Heinrich Klüver, who produced optical hallucinations through mescaline. Klüver's subjects reported seeing gratings, lattices, fretwork, filigree, honeycombs, chessboards, cobwebs, funnels, spirals, etc. $[9,14]$.

The pervasive presence of geometrically simple shapes puts the ornamentalism of psychotic art work in the proper context. Under normal circumstances the tendency toward simplicity tends to be modulated by the multiformity of outer and inner stimulation. In the arts this tendency manifests itself as "form" at various degrees of abstraction, which can be oriented toward or away from the outer world. Abstraction as a consequence of detachment from the world of exogenous experience derives from a variety of psychological and social causes. Paul Klee, in a diary note of 1915 , pointed to one of those causes, particularly significant for our purpose: "The more terrifying the world (as 
precisely today) the more abstract the art, whereas a happier world creates an art of the here and now... In the large pit of shapes some fragmentary debris remains, to which one is still partially attached. It furnishes the material for abstraction" (8, \#951). And one of Navratil's patients formulated succinctly: "Being forced to do things is doing something on one's own when there is no external compulsion of circumstance but only an anatomical-geometrical coercion" (4, p. 112). In some of the last drawings and paintings of Vincent van Gogh one can see highly ornamental shapes stifling the rendering of natural objects to an extent that chills the lively expression so happily present in the artist's earlier work. It is as though the endogenous form categories of the mind erect too impermeable a barrier between perception and object.

The creators of the more arresting works of psychotic art range all the way from totally or largely uneducated and untrained persons to professional artists. Widely known are the cat pictures of the English commercial illustrator Louis Wain, whose lifelong insistence on a single subject offers the rare opportunity to watch the dramatic development from slick naturalism and caricature to the gradual drowning of the cat image in a carpetlike terrifying ornamentation - works of much greater originality and aesthetic integrity than anything the artist had produced before $(4$, p. 152). Two Swedish painters, whose work was rooted in the conventions of the nineteenth century, underwent a spectacular liberation of their imaginative power, together with some desintegration of form. In the psychotic state both created haunting images, whose affinity to the styles of Expressionism and Surrealism brought them new recognition by later generations. An exhibition of the work of Ernst Josephson (1851-1906) drawn from Swedish and Norwegian collections was organized in 1964/65 and circulated in museums of the United States $(12 ; 4$, p. 145). In 1976 the Museum in Malmö presented a large retrospective of Carl Fredrik Hill, who lived from 1849 to $1911(7 ; 4$, p. 137). In comparing the psychotic with the pre-psychotic work of these artists one cannot help feeling that in both cases a totally different personality, a totally different artist received the posthumous homage - someone hardly identical with the relatively undisturbed person that had begun a respectable but much less remarkable career a century or so earlier.

In keeping with what I have said so far, much of the better work of severely disturbed mental patients cannot be identified as such with any certainty or distinguished from the work of perfectly normal modern artists. This is not an argument against modern art but in support of the re-evalu. ation of the diseased mind initiated by Prinzhorn and the psychiatrists and artists of his generation.

But it also cannot be denied that, on the other hand, mental institutions generate innumerable art products that any person familiar with such matters will identify at first glance as what they are. Even so, it seems justifiable to assert that the clues for such recognition are mostly secondary, in the sense that they are not directly expressive of the nature of mental disease but rather indirect, circumstantial consequences. Among such give-aways I mention the combination of crudely dilettantish representations and boldly sophisticated arrangements of themes, or the inability to control freely expressive colors and shapes beyond a limited range of spatial composition. Instead of an organized whole one sees agglomerations of items strung together by a constantly shifting attention, which is incapable of integrating an extended whole. (But even this criterion can be applied only with some reservation. Not only does such a lack of unity often result from a lack of artistic quality in perfectly normal products; one must also keep in mind that the purpose of the work does not always call for compositional unity. For example, many of the drawings Jackson Pollock made for his psychiatrist contain separate notations or sketches on the same sheet of paper [15]. By no means does this indicate a lack of mental integration.) There is also the telltale use of writing in pictures, not as a sensitively applied ingredient of visual composition - as in Far-Eastern or Cubist painting - but as reckless, unconcerned communication. Characteristic is furthermore the reliance on standardized symbols, verbal as well as visual.

Needless to say, the bulk of the art of patients consists of pathetically trivial scribbles, indicative not of the maker's illness but of the sad state of a culture, which fails to develop the average person's natural sense of form. What then is it that occasionally makes an equally untrained or mistrained person break through the dead crust of triteness and attain the powerful originality we have been discussing? Surely it is not the severity of the patient's pathology. Is it simply a matter of "talent," whatever the origin of such happy but mysterious gift may be? I believe that at present we have no 
answer to this question. However, I was glad to see that Dr. Navratil, on the basis of his practical experience, objects to the notion that art therapy has nothing to do with art: "I endeavor to discover the special talent of a patient, first of all for a therapeutic reason: it must matter whether a person can express himself with particular means in a clear and differentiated fashion or whether such a medium does not exist for him" (4, p. 282).

A last observation should refer to this much debated relation between artistic creativity and psychosis. The notion of "the poet's eye, in a fine frenzy rolling," goes back to antiquity and, in a more scientific-looking garb, attracted much attention in the nineteenth century. Our own discussion reflected the conviction that psychosis can act as a catalyst releasing potential resources of imagination and formal organization. In this view, mental disease does not generate artistic genius but provides access to a given endowment of the mind. Perhaps it also steers the conception of the art work in directions determined by the nature of the disturbance, e.g., in paranoia. In recent years Roland Fischer has proposed a temptingly simple linear relationship between creativity and illness (14, ch. 6). A scale of physiological arousal leads from normal perception to states of rapturous ecstasy. The levels of arousal are said to be indicated by "a decrease in variability of the EEG amplitude, measured as the coefficient of variation, which decreases from 35 to 7 ..." (For a clearer formulation see Berlyne [5] p. 65). On this scale artistic activity is placed somewhat above normal perception and below acute schizophrenia. The theory implies that the various mental states here involved are distinguished from one another by a purely quantitative measure of intensity.

Arousal has become a favorite subject of recent experimental work in aesthetics, especially in the work of D. E. Berlyne (5, ch. 7). Historically arousal represents the physiological, and therefore measurable, counterpart of "emotion," which became a key concept of aesthetics during the last century and of clinical psychology in our own time. It seems to me that the difficulties besetting any psychology based on "emotions" are likely to affect also this latest version of such an approach. The translation of the theory into physiology spells out an underlying assumption that remained tacit in the more psychological formulations, namely that the complex mental processes at issue can be reduced to the unspecific dimension of organic tension or arousal levels. In a paper on this subject I have tried to show that such an approach confines itself to a secondary symptom rather than dealing with the principal processes (2, pp. 302 ff.) This is true for artistic activity and should hold equally for other mental states, such as psychosis or the ecstasy of the mystic. It is not emotion that generates art, just as it is not emotion that generates mental disease. On the contrary, it is the particular motivational and cognitive processes of which these mental states consist that generate the arousal state of emotion as a secondary symptom.

No simple quantitative expedient can release us from the task of analyzing the artist's particular way of looking at the world and his particular ways of coping with the challenges and opportunities of human existence. The same is true for our understanding of mental disease. Only after we have sufficiently advanced in tackling both these psychological tasks can we hope to clarify the relation between the most exalted and the most wretched state of the human condition.

\section{REFERENCES}

1. ARIETI, SILVANO (1976) Creativity, the Magic Synthesis. New York: Basic Books.

2. ARNHEIM, RUDOLF (1966) Toward a Psychology of Art. Berkeley and Los Angeles: University of California Press.

3. BADER, ALFRED (ED.) (1975) Geisteskrankheit, bildnerischer Ausdruck und Kunst. Bern: Huber.

4. BADER, ALFRED AND LEO NAVRATIL (1976) Zwischen Wahn und Wirklichkeit. Luceme: Bucher.

5. BERLYNE, D. E. (1971) Aesthetics and Psychobiology. New York: Appleton-Century-Crofts.

6. EHRENZWEIG, ANTON (1953) The Psychoanalysis of Artistic Vision and Hearing. New York: Julian.

7. HÖGESTÄTT, EJE (1976) Carl Fredrik Hill. Malmö: Kunsthall.

8. KLEE, FELIX (ED.) (1968) The Diaries of Paul Klee 1898-1918. Berkeley and Los Angeles: University of California Press.

9. KLÜVER, HEINRICH (1966) Mescal and Mechanisms of Hallucinations. Chicago: University of Chicago Press.

10. KNOLL, MAX (1958) Anregung geometrischer Figuren und anderer subjektiver Lichtmuster in elektrischen Feldern. Schweizer Zeitschr. Psych. und Anwend., 17, pp. $110 \mathrm{ff}$.

11. MORGENTHALER, WALTER (1921) Ein Geisteskranker als Künstler. Bern: Bircher.

12. NEWTON, FRANCIS J. (1964/65) Paintings and Drawings by Ernst Josephson. Portland (Oregon): Art Museum.

13. PRINZHORN, HANS (1972) Artistry of the Mentally $m$. New York: Springer, 1972.

14. SIEGEL, RONALD K. AND LOUIS JOLYON WEST (ED.) (1975) Hallucinations. New York: Wiley.

15. WYSUPH, C. L. (1970) Jackson Pollock: Psychoanalytic Drawings. New York: Horizon. 